\title{
TO REMAIN, MIGRATE ABROAD OR RESETTLE: A COMPLEX DYNAMIC PROCESS AFFECTING PAKISTANI PHYSICIANS' CAREER DECISIONS
}

\author{
Muhammad Arifl, Mary Cruickshank2, John Fraser ${ }^{3}$ \\ 1. Qassim University 2. Federation University 3. University of New England \\ Correspondence: ma.hajj@qu.edu.sa
}

\begin{abstract}
OBJECTIVE

This study investigated Pakistani physicians' decisionmaking concerning their decisions to stay in Pakistan, migrate abroad, or resettle back into their country after working abroad.
\end{abstract}

\section{METHODS}

This qualitative study employed a phenomenological research design. Thirteen Pakistani physicians characterised as 'stayers', 'leavers' and 'resettlers' were interviewed via telephone to explore their lived experience in 2008-2009.

\section{RESULTS}

Results show a dynamic nature of the physicians' career decision-making depending on their constant weighing of complex personal, family, professional and societal factors. Stayers, leavers and resettlers are not mutually exclusive groups but rather individual physicians' can move between these groups at different stages of career and life. Physicians vary in their decision making. Stayers and resettlers place more emphasis on personal and family reasons and societal factors providing there is a permanent job for them. Leavers focus on health system problems and recent societal problems of personal and societal insecurity.

\section{CONCLUSIONS}

The findings of this study indicates that physician migration, retention and resettlement is a complex issue and there are multiple personal, social, political and economic factors that affect their decisions to stay, move abroad or resettle back into their countries. Therefore, it is recommended that future research focusing on health workers retention, migration and resettlement issues look at it from a holistic perspective rather than focusing only on the economic and professional imperatives. The findings of this study have international implications for health care managers dealing with a highly mobile international medical workforce. Strategies considering different stages of the physician career/ life cycle need to highlight the importance of identity, belonging and place as doctors weigh this with career goals.

\section{KEYWORDS}

Career decision-making; Doctors; Overseas migration; Physicians; Recruitment; Retention; Resettlement; Pakistan

\section{INTRODUCTION}

The misdistribution of highly skilled health professionals including physicians, both within a country and internationally, is of growing concern globally because of its impact on health systems in developing and developed countries alike. This has become a near universal problem, particularly in developing countries. Shortages in health care staff have intensified as a result of both the emigration of health care workers from developing to developed countries and the intra-country imbalances between rural and urban areas. [1-4] 
As identified in the literature, low salaries, shortages of supplies and work overload leading to unsatisfactory work conditions, political instability, insecurity, poor living conditions, inadequate social services, poor education services for children and lack of continued professional development are some of the economic, political and social factors influencing health professionals to migrate. [5-8] However, much less is known about the factors that influence physicians' decisions to either stay in their countries, migrate abroad or re-settle back into their countries after living and working for some time in another country.

Overseas trained health care professionals represent more than a quarter of the medical and nursing workforces of Australia, Canada, the UK and the USA. [9] International medical graduates (IMGs) constitute 23-28 percent of physicians in the USA, Canada and Australia, and lower income countries supply 40-75 percent of these IMGs. [10$11]$

Pakistan faces a shortage of physicians particularly in rural areas of the country. [12-13] Despite this local need, beside India and the Philippines, the majority of migrant physicians working in the United States, the United Kingdom, Canada and Australia are of Pakistani descent. [14] According to an estimate, out of 5400 graduates in 2016 around 1100 physicians have left the country and this trend is expected to increase further. [12] Furthermore, according to the Joint Learning Initiative (JLI) report, Pakistan is among the 45 countries in the world that is suffering from an acute shortage of health workers (doctors, nurses and midwives), which is defined as less than 2.5 workers per 1000 population, and high-mortality rates. [15]

This study was conducted in an effort to fill this gap and broaden the base of systematically collected data on physician migration and retention in a developing country context. Therefore, the purpose of this study was to explore the perceptions of Pakistani physicians regarding their career decision to remain in their country, migrate abroad or resettle back into their country after working abroad for some time. The focus is on understanding the Pakistani physicians' interpretations of their personal, professional and societal experiences that affected their career decision about whether to stay in their country, migrate abroad or resettle back into their country after working and living abroad for some time.
In order to address the purpose of this study, which is to explore the reality, perceptions and the lived experiences of Pakistani physicians, four specific aims were developed. These aims were to i) explore the perceptions of Pakistani physicians regarding their career decision to remain in their country and not move overseas; ii) explore the perceptions of Pakistani physicians regarding their career decision to migrate abroad; iii) explore the perceptions of Pakistani physicians regarding their career decision to initially go abroad and then resettle back to their country and iv) identify the problems encountered by Pakistani physicians during the process of resettlement back into their country after working abroad for some time.

This first overview paper presented here is a part of a larger study conducted by the principal investigator as part of his doctoral thesis, which is freely available online. [16] Therefore, for the purpose of this paper; only the major findings and conclusions that address the overall purpose of the study will be presented and discussed. Other findings that address the four specific aims will be presented in subsequent publications.

While the results of this study were obtained in 2009-2010, this paper argues that they are still relevant and add to literature on human resources for health in Pakistan. A recent paper by Siddiqui et al. [17] recommends using locally developed career decision instruments relevant to the Pakistan situation. Similarly, Malik et al. [18] recommends further studies using exploratory methods to understand the underlying factors for Pakistani physician's recruitment, retention and migration decisions. Furthermore, the results of this paper are particularly relevant with the devolution of health care to provinces in Pakistan with human resources for health strategies being developed in provinces. [19]

\section{METHODS}

\section{STUDY DESIGN}

This qualitative study employed hermeneutic phenomenology as the research design. This interpretive research design was chosen because it provides the most appropriate design to research the lived experience from the unique perspective of the individual at a particular point in time. The intention of this study was not to quantify the process of decision-making but rather to draw out the experiences of the individual doctors about their career 
decision to remain in Pakistan, migrate overseas or resettle back into Pakistan.

\section{STUDY SETTING AND POPULATION PROFILE}

This study was conducted via telephone interviews in both Pakistan and Australia. Semi-structured interviews were conducted with Pakistani physicians working in the four provinces of Pakistan namely Khyber Pakhtunkhwa (formerly North West Frontier Province), Balochistan, Punjab and Sind and in the states of New South Wales, Queensland and Western Australia in Australia. The population for this study consisted of Pakistani physicians who obtained their primary medical qualification from Pakistan and were working as physicians either in Pakistan or Australia at the time of the study.

In line with the aim of the study, the population of interest was divided into three broad categories that is, 'Stayers', 'Leavers' and 'Re-settlers'. 'Stayers' were those Pakistani physicians who obtained their primary medical qualification in Pakistan, had never migrated to another country and were working in Pakistan at the time of this study. 'Leavers' were those Pakistani physicians who obtained their primary medical qualification in Pakistan and at the time of the study were working in Australia. 'Re-settlers' were those Pakistani physicians who obtained their primary medical qualification in Pakistan, had migrated to another country and had re-settled back and were working as physicians in Pakistan at the time of this study.

\section{DATA COLLECTION PROCEDURE}

Data was collected between September 2008 and July 2009. Semi-structured interviews were conducted with 13 participants who were selected using a combination of both purposive and snow-ball sampling. Before actual data collection, two pilot studies were conducted to ensure that the informants understand the intended meaning of the questions and the researcher understands the informant's answers, to identify problems and also to add to reliability through pre-testing. [20-21] The interviews were conducted via telephone using the interview schedule and audiotaped with participant permission. All the interviews were conducted either in English, Urdu (Pakistan national language) or Pushto (one of Pakistan's regional languages) as desired by the participants. These were then translated and transcribed in English by the principal researcher. The translated transcripts were shared with the participants for validation and to confirm if the researcher has correctly captured their lived experiences.
All the participants were medical doctors and were educated with English as their first language and were well versed with the English language.

\section{DATA ANALYSIS}

A thematic analysis technique was used to analyse the interview transcripts. Data analysis commenced along with the data collection, as in a qualitative study, data collection and data analysis are interrelated processes. [22-23] The principal researcher then read and re-read the transcripts highlighting and coding those words, phrases or passages of interview content that addressed the study aims. These were then categorised into themes in order to provide a clear description of the experiences of Pakistani physicians' as Stayers, Leavers or Re-settlers.

After conducting the transcription and coding of each set of two to three interviews by the principal researcher, the transcripts were then read and coded individually by two other researchers. The results of this analysis by the three researchers were compared in review meetings and any differences were discussed until agreement was reached. This use of multiple researchers during the data analysis increased the rigour and trustworthiness of the data.

Rigour and trustworthiness of the data were maintained by using the criteria of credibility, transferability, dependability and confirmability. [24] Credibility of the study was addressed by prolonged engagement with the study participants before and during the interviews, through respondent validation, by providing a copy of the respective transcript to the study participants to provide feedback and to make any clarification or change to the written transcript. Credibility was further enhanced by presenting the preliminary findings of this study at two conferences at the University of New England, Australia to obtain peer review. Transferability was addressed by providing a detailed description of the relevant literature, study methodology together with the settings and the data collection methods, data analysis, findings and conclusions. Dependability and confirmability were achieved by systematically managing the study records that constituted an audit trial.

\section{ETHICAL CONSIDERATIONS}

Approval to conduct this study was obtained from the University of New England's Human Research Ethics Committee. Willing participants were approached by the principal researcher and provided an information sheet and consent form. Informed consent was given for the 
interviews to be audiotaped and pseudonyms were used to de-identify the participant in the transcriptions.

\section{RESULTS}

The factors that affected Pakistan physicians' career decisions are clustered into three categories as themes and subthemes: personal characteristics and family factors, health system factors and societal factors. In some of the categories, no factor was identified by the participants during their discussions.
The study results showed that the main personal and family factors that influence Pakistani physicians' decision to stay in their country were their identity and belonging to their country and culture, a desire to serve their own people, their family attachment and the availability of family support in Pakistan. The health system factor that influenced their retention decision was having a permanent job in Pakistan and a societal factor of their perception of differentiation between locals and nonlocals abroad (Table 1).

TABLE 1: FACTORS INFLUENCING PAKISTANI PHYSICIANS' CAREER DECISIONS TO REMAIN IN THEIR COUNTRY AND NOT MOVE OVERSEAS

\section{CATEGORY FACTOR}

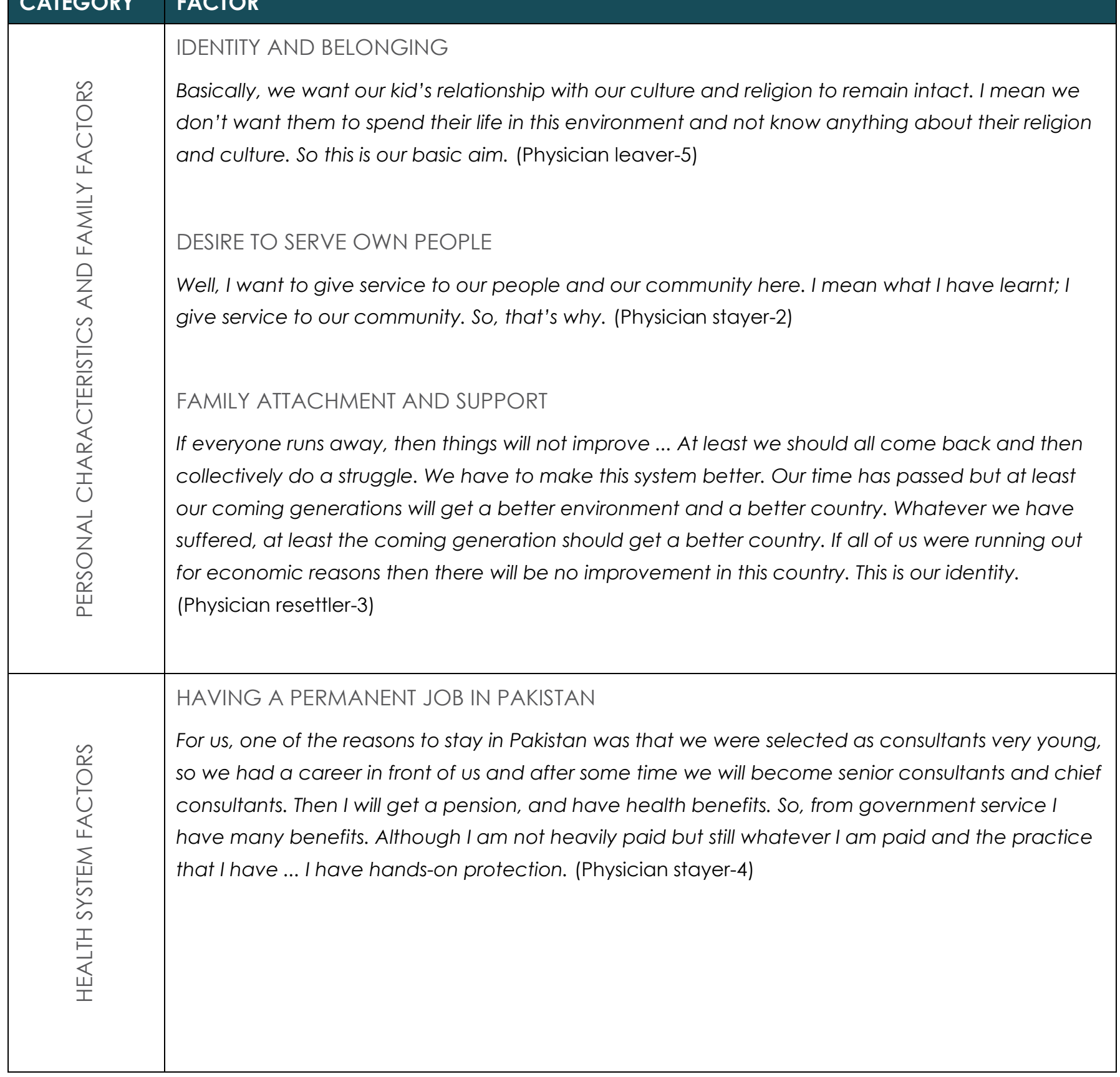




\begin{tabular}{|c|c|}
\hline & $\begin{array}{l}\text { LESS DIFFERENCE BETWEEN LOCAL AND OVERSEAS EARNINGS } \\
\text { Well even abroad I will get the same package of PKR 100,000 to PKR 150,000 per month which } \\
\text { with my private practice I am getting here too. So, I think one should not waste time abroad and } \\
\text { instead give time to one's own private set up. } \\
\text { (Physician stayer-3) }\end{array}$ \\
\hline 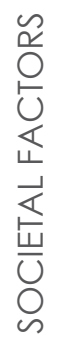 & $\begin{array}{l}\text { PERCEPTION OF DIFFERENTIATION BETWEEN LOCALS AND NON-LOCALS } \\
\text { Abroad, we are hearing from people that there is a difference between local and non-locals and } \\
\text { even in Arab countries between Arabs and non-Arabs. And in European countries, I have heard } \\
\text { from some doctors that when you are travelling in a bus, the English person will not sit with you on } \\
\text { the same seat and instead will sit on another seat and your seat will remain empty. So, you feel } \\
\text { very strange. (Physician stayer-3) }\end{array}$ \\
\hline
\end{tabular}

Those Pakistani physicians who left their country and went overseas did so mainly because of health system problems and a few societal factors. The health system factors identified were lack of health human resource policy and planning, lack of availability of good postgraduate medical training, poor career structure, less professional development opportunities and lower salaries to these doctors in Pakistan. The societal factors that compelled these physicians to leave their country were the nonrecognition of health as a state priority, a culture of valuing overseas training and increasing personal insecurity and societal degradation in Pakistan (Table 2).

Similarly, the results of this study also revealed several factors that encouraged Pakistani physicians who had gone abroad for further studies or work to resettle back into their country. These factors included a perception of a better quality of life in Pakistan as compared to overseas, the availability of a permanent job in Pakistan and feelings of differentiation between locals and non-locals abroad (Table 3).

TABLE 2: FACTORS INFLUENCING PAKISTANI PHYSICIANS' CAREER DECISIONS TO MIGRATE ABROAD

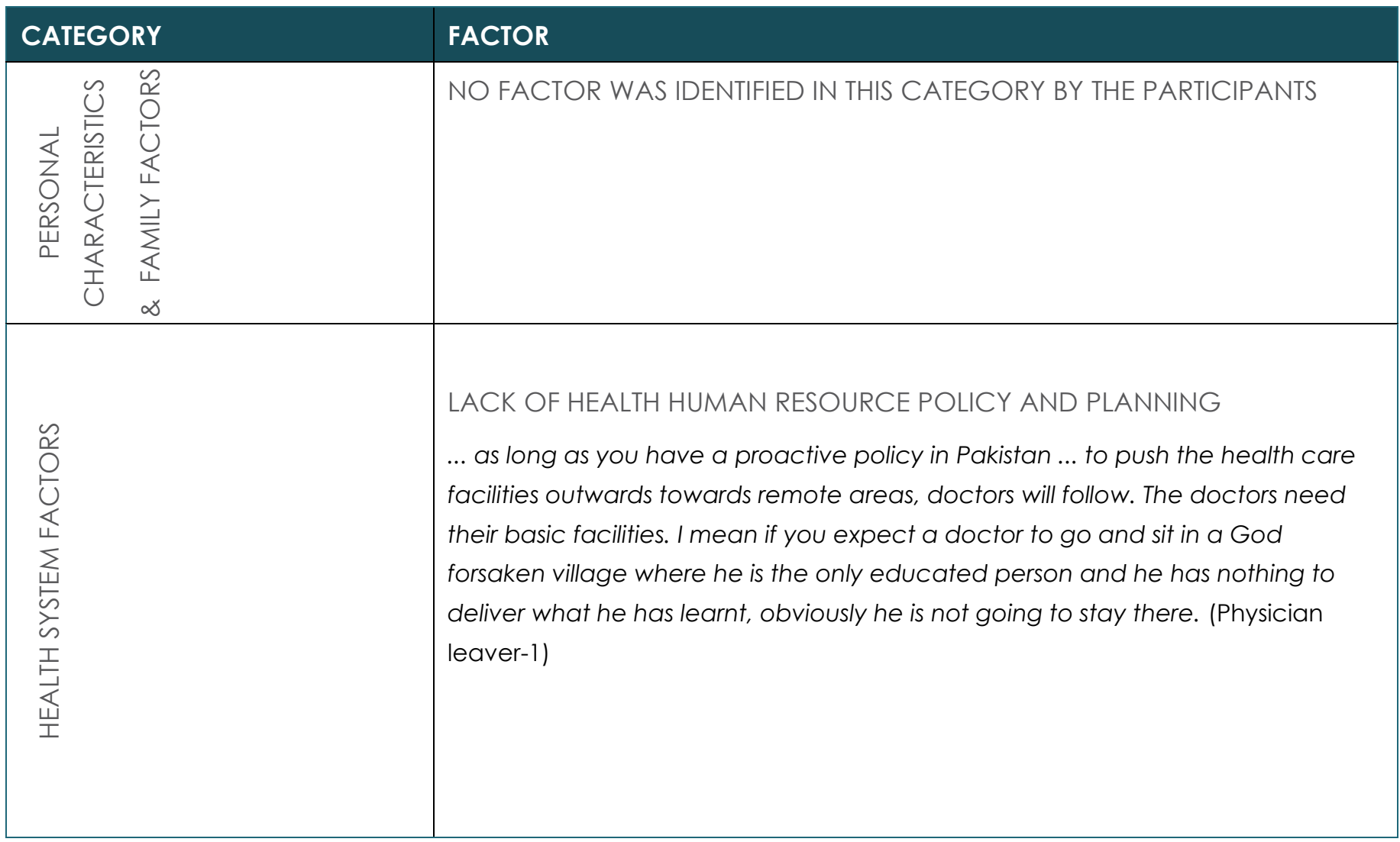




\begin{tabular}{|c|c|}
\hline & $\begin{array}{l}\text { LACK OF GOOD POSTGRADUATE MEDICAL TRAINING } \\
\text { There is a lot of difference. Our [Pakistani] training is not at all structured. Our } \\
\text { training is just like an apprenticeship, like here you sit a child with a mechanic so } \\
\text { that he will learn at least something. It is the same here ... There is no structured } \\
\text { training. (Physician resettler-3) } \\
\text { LACK OF PROPER CAREER STRUCTURE AND PROFESSIONAL DEVELOPMENT } \\
\text { There is training and then there is career progression. So, that was not like that. } \\
\text { That was just a job but that was not useful for career progression. (Physician } \\
\text { leaver-3) } \\
\text { LOWER SALARIES } \\
\text {... in Pakistan you do medicine in } 7 / 8 \text { years and then you do house job and } \\
\text { training after doing graduation, and when you have not reached the consultant } \\
\text { level you can't support your family. And especially for males where they are the } \\
\text { only earning member, they can't support their families on their salary. (Physician } \\
\text { leaver-5) } \\
\text { OVERSEAS DEMAND } \\
\text { Then after that [graduation and internship] I was unsure whether to go to } \\
\text { America or England. That was the time when you had a lot of choice. You could } \\
\text { go anywhere. In England at that time you could get full registration ... so for } \\
\text { postgraduation I went to England. (Physician leaver-4) }\end{array}$ \\
\hline 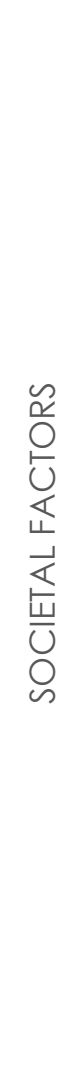 & $\begin{array}{l}\text { HEALTH AS A STATE PRIORITY } \\
\text {... YOu know in Pakistan the disparity between your major cities and rural areas is } \\
\text { tremendous. Your health care in Peshawar [provincial capital of NWFP] is } 21 \text { st } \\
\text { century while your healthcare in Data Khel village which is } 200 \text { miles [from } \\
\text { Peshawar] is Stone Age. So, the disparity is tremendous and that needs } \\
\text { investment and in a country that is struggling for all sorts of economic } \\
\text { development, health is a fourth/fifth priority. It should be first, but it is a fourth and } \\
\text { fifth priority. (Physician leaver-1) } \\
\text { CULTURE OF VALUING OVERSEAS TRAINING } \\
\text { Our people have this psyche that when someone does something abroad it has } \\
\text { a good impression on the people in Pakistan. So, then people are interested in } \\
\text { doing their degrees abroad. (Physician leaver-5) } \\
\text { PERSONAL INSECURITY AND SOCIETAL DEGRADATION } \\
\text { Now, I am saying that I am satisfied economically with my job. So, it is sometimes } \\
\text { because of the security situation that I think about going abroad, otherwise, } \\
\text { now economically there is not much difference for me. (Physician stayer-3) }\end{array}$ \\
\hline
\end{tabular}




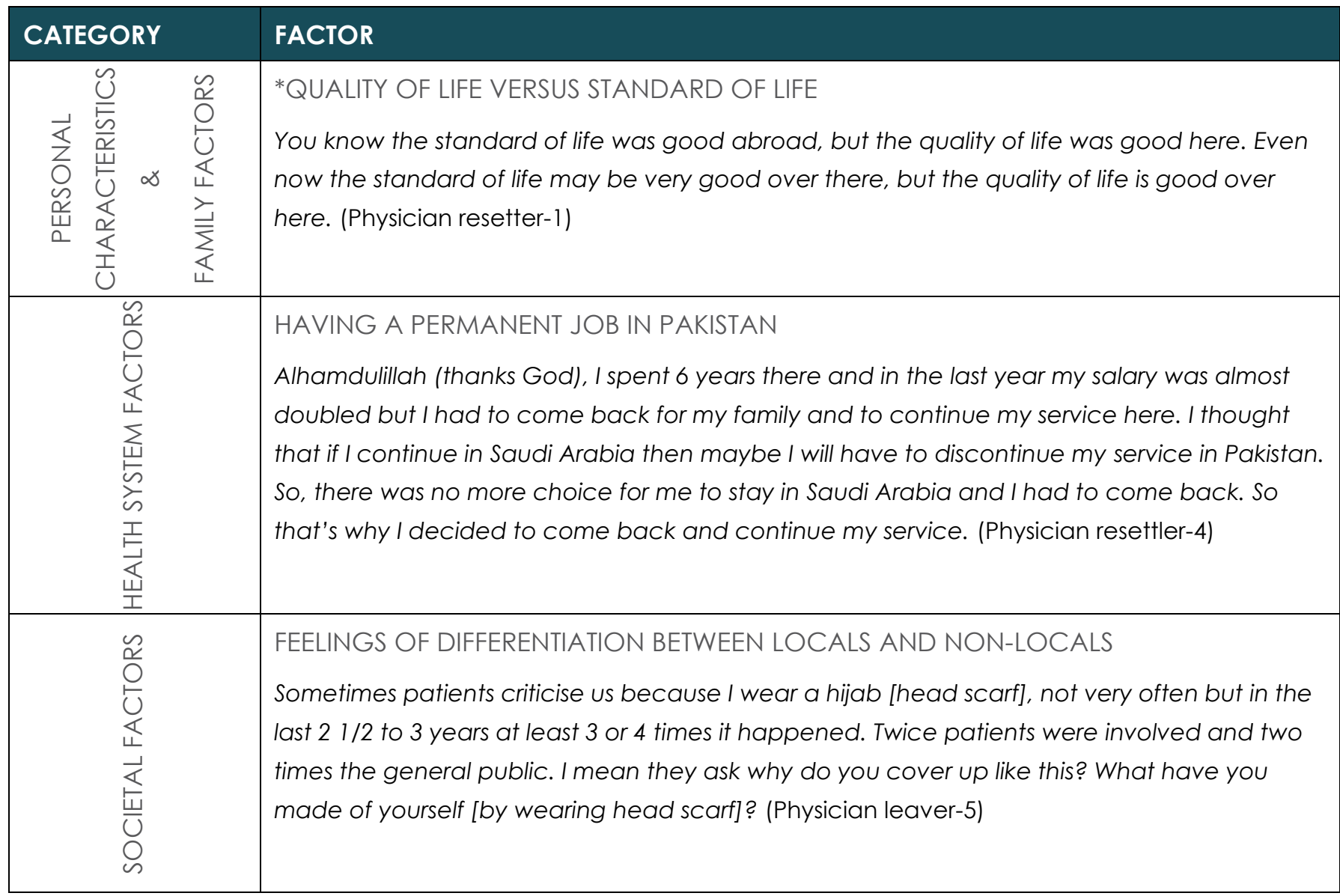

Furthermore, the study results identified the problems faced by Pakistani physicians during the process of resettlement in Pakistan, which addressed the fourth aim of the larger study. These problems were mainly health system problems, such as an unwelcoming attitude on the part of hospital management both in the public and private sectors, difficulty in finding suitable jobs and the availability of underpaid jobs. Furthermore, the increasing personal insecurity and societal degradation was also identified as potential problems that discourage Pakistani physicians from resettling (Table 4).

\section{DISCUSSION}

Three significant findings emerged from the data analysis. First, the study shows the dynamic nature of the physicians' career decision-making which depends on the constant weighing of complex personal, family, professional and societal factors. Second, those physicians who decided to stay in Pakistan or resettled back into Pakistan did so because of their personal and family reasons or because of societal factors. Health system factors played a minimal role in the decisions of these physicians, except for the availability of permanent jobs. The third major finding that emerged from the study is that the factors affecting Pakistani physicians' decisions to move overseas or barring those from coming back into their country after training or working abroad for some time are mostly health system problems with the addition of another societal problem of personal insecurity and general societal degradation. However, as stated in the introduction section of this paper, only the first major finding which addresses the overall purpose of this study is discussed. Other findings that address the four specific aims will be presented in subsequent publications.

\section{THE DYNAMIC NATURE OF PHYSICIANS' CAREER DECISION-MAKING}

From the findings of this study, it is clear that physician migration, retention and re-settlement is a complex issue and there are different social, political and economic factors that affect their decisions of moving abroad, resettling back or staying in their country. 
TABLE 4: PROBLEMS ENCOUNTERED BY PAKISTANI PHYSICIANS DURING THE PROCESS OF RESETTLEMENT BACK INTO THEIR COUNTRY AFTER WORKING ABROAD FOR SOME TIME

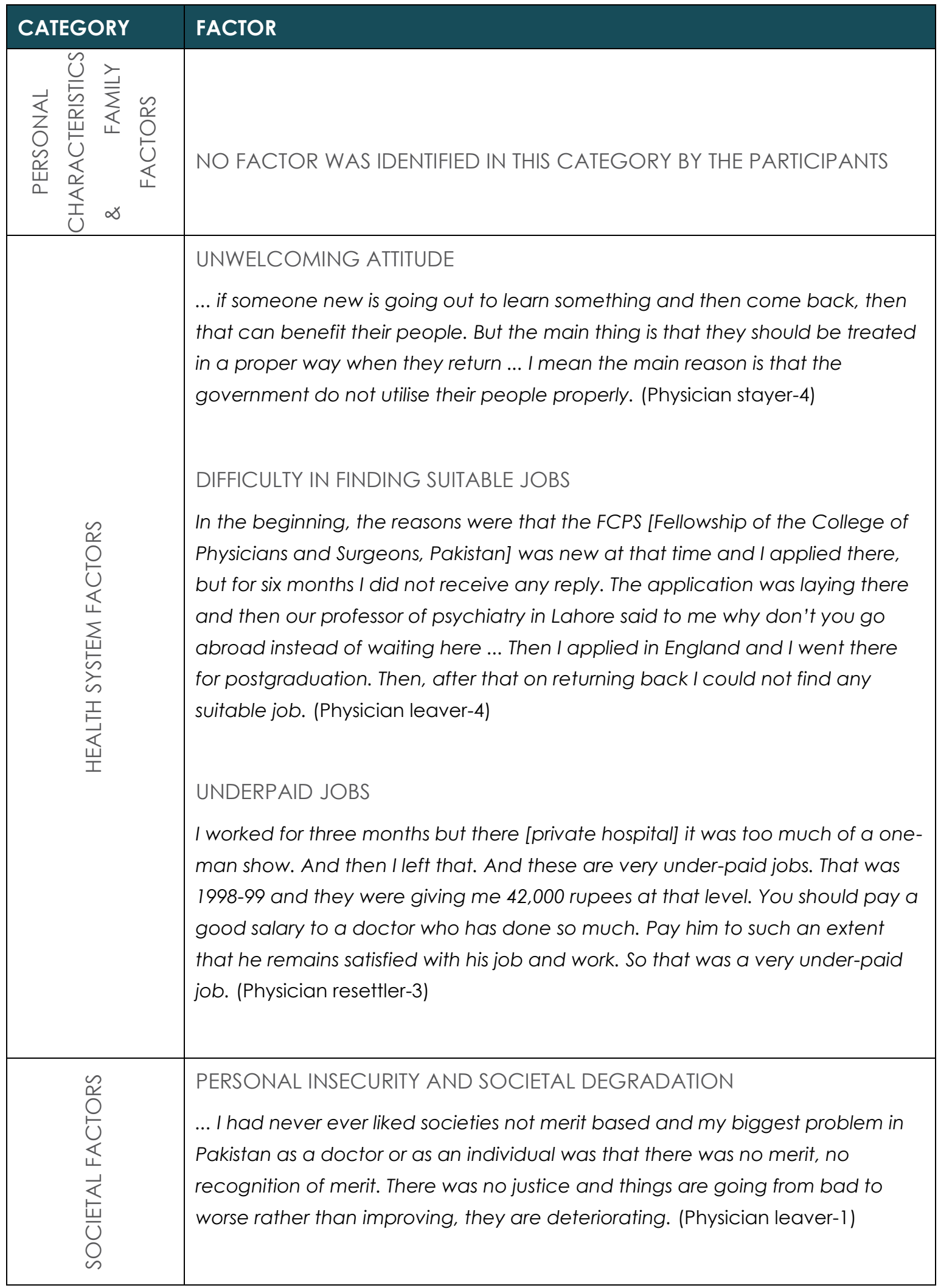

The first major conclusion from this study which addresses the overall purpose of this study suggests that the three groups of respondents, stayers, leavers and resettlers, interviewed for this study are not static and mutually exclusive entities. During the course of their career journeys these physicians continuously evaluated their personal, professional and social circumstances and made their career decisions based on these different conditions. 
Based on these multiple and complex factors, those physicians that are happy with their life, work and family balance stay, while those that are unhappy with the balance and have different priorities, move abroad. Likewise, those who go overseas and achieve their predominantly professional goals, such as postgraduate training or increased monetary benefits, tend to stay overseas. In the meantime, if their priorities change, such as their perceived better quality of life in their home country as compared to overseas, then they resettle back into their country of origin. Similarly, those physicians who resettle back into their country can leave again depending on their analysis of the available conditions in their home country. Therefore, based on this constant weighing up of these multiple circumstances a stayer physician can become a leaver and a leaver can become a resettler and, depending on the prevailing conditions, even a resettler physician can become a leaver again.

This finding about Pakistani physicians' evaluation of multiple personal, family, professional and societal factors during their career decisions has similarities with decisionmaking behavioural models proposed by Wolpert et al. [25] and Tolhurst [26] 'Landscape of Fulfilment' model. According to behavioural models, migration decisions are a sort of individual cost-benefit analysis that not only includes economic factors but other non-economic societal factors such as security and self-fulfilment. [25] According to this model, a person will only migrate if his/her values and expectations are met at the destination.

Similarly, according to the Tolhurst's of 'Landscape of Fulfilment' model, individual doctors seek the balance between the notion of the 'self' that encompasses their internal inspirations and values with the other domains that relate to aspects of life and work. [26] Therefore, this model argues that, based on this balance between self, life and work expectations, doctors make decisions about staying or leaving their practice locations.

While Abdullah et al. [27] critically reviewed human resources for health as a crisis for Pakistan, the solutions rely on the importance of understand the interplay of recruitment, retention and migration. Our qualitative paper explores the lived experience of Pakistani physicians as they change from stayers, leavers and resettlers and outlines that decision making is dynamic with the weighing of personal and family factors, societal and environmental factors. The findings of Sheikh et al. [5] in a qualitative study of Pakistani doctors who were early migrators found similar factors at play. These factors are not isolated to doctors alone, but also extend to primary health care workers in Pakistan. [28] Other recent quantitative studies have found personal and family, and societal and environmental issues important for career decision making for both medical students [29] and doctors in Pakistan. [18]

The findings of this study have important implications for policy and practice in relation to health human resource development generally and the medical workforce particularly in Pakistan and also other similar developing countries. It is important to note that Pakistan is not the only country facing problems with health human resource recruitment, retention and migration. Globally, countries in both the developed and the developing world are struggling with efficient and effective use of its human resources for health. [1-4] Therefore, the issues raised in this study, which can be viewed as a case study of Pakistani physicians, may be generalisable to doctors from other countries. This is supported by the importance of identity, belonging and place emphasised both in our findings relating to Pakistani physicians and by Tolhurst [26] who studied Australian medical students and female physicians.

While this study focuses on Pakistani doctors, its findings has relevance to health care managers internationally because Pakistani physicians make a major proportion of migrant physicians working in the United States, the United Kingdom, Canada and Australia. [14] Therefore, health managers in recipient countries should consider issues which have made their new doctors leave their country of origin to assist in their transition and retention in a new country.

Alternatively, health managers in developed countries, who are major recipients of Pakistani and other similar developing countries doctors, may develop bilateral agreements for developing professional training programs for these migrating physicians on the condition of return. It will help these migrating physicians by increasing their earnings and also by getting trained by working for some years in an advanced healthcare system under supervision. On the other hand, the recipient countries will get much needed healthcare workers that will provide healthcare to their people. Therefore, such agreements could be beneficial for both the source and the recipient country. 


\section{CONCLUSION}

Physician migration, retention and resettlement is a complex issue and there are multiple personal, social, political and economic factors that affect their decisions to stay, move abroad or resettle back into their countries. Therefore, it is recommended that future research focusing on health workers retention, migration and resettlement issues examine it from a holistic perspective rather than focusing only on the economic and professional imperatives.

\section{References}

1. Mir AM, Shaikh MS, Rashida G, Mankani N. To serve or to leave: a question faced by public sector healthcare providers in Pakistan. Health Res Policy Syst 2015;13(Suppl 1):85-91.

2. Araujo EC, Maeda A. How to recruit and retain health workers in rural and remote areas in developing countries: a guidance note. Washington DC: Health Population Nutrition, Human Development Network, World Bank; 2013 June. Discussion Paper No.:78506.

3. Salafsky B, Glasser M, Ha J. Addressing issues of maldistribution of health care workers. Ann Acad of Med Singapore. 2005; 34:520-525.

4. Lancet. Medical migration and inequity of health care. Lancet. 2000;356(922):177.

5. Sheikh A, Naqvi HA, Sheikh K, Naqvi HS, Bandukda $M Y$. Physician migration at its roots: a study contributing towards a career choice abroad among students at a medical school in Pakistan. Global Health. 2012;8(43):1-11.

6. Akl EA, Maroun N, Major S, Afif C, Chahoud B, Choucair J, et al. Why are you draining your brain? Factors underlying decisions of graduating Lebanese medical students to migrate. Soc Sci Med. 2007; 64:1278-1284.

7. Hagopian A, Ofosu A, Fatusi A, Biritwum R, Essel A, Hart LG et al. The flight of physicians from West Africa: views of African physicians and implications for policy. Soc Sci Med. 2005; 61:1750-1760

8. Bundred PE, Levitt C. Medical migration: who are the real losers? Lancet. 2000;356(9225):245-246.
9. Kingma M. 2005. Migration patterns of health professionals. Cah Sociol Demogr Med. 2005;45(23):287-306.

10. Chen LC, Boufford JI. Fatal flows - doctors on the move. N Engl J Med. 2005;353(17):1850-1852.

11. Hagopian A, Thompson MJ, Fordyce M, Johnson $K E$, Hart LG. The migration of physicians from subSaharan Africa to the United States of America: measures of the African brain drain. Hum Resour Health. 2004;2(17):1-10.

12. Shah SM, Zaidi S, Ahmed J, Rehman SU. Motivation and retention of physicians in primary healthcare facilities: a qualitative study from Abbottabd, Pakistan. Int J Health Policy Manag. 2016;5(8):467-475.

13. World Health Organization. World Health Report: Working Together for Health. Geneva: World Health Organization; 2006.

14. Mullan F. The metrics of the physician brain drain. N Engl J Med. 2005;35(17):1810-1818.

15. Joint Learning Initiative. Human Resources for Health: Overcoming the Crisis. Global Equity Initiative Harvard University; 2004

16. Arif M. To remain, migrate abroad or resettle: an exploratory study of Pakistani physicians' career decisions [Doctoral thesis]. Armidale (NSW): University of New England; 2011. Available from https://epublications.une.edu.au/vital/access/manag er/ Repository/une:7328

17. Siddiqui ZS. Application of career related research in Pakistan: the case of apples vs mangoes. Pak J Med Sci. 2016;32(3):773-777.

18. Malik AA, Yamamoto SS, Souares A, Malik Z, Saverborn R. Motivational determinants among physicians in Lahore, Pakistan. BMC Health Serv Res. 2010;10(201):1-11.

19. Global Health Workforce Alliance [Internet]. Geneva: Country Responses: Pakistan [updated 2017; cited 2017 March 24]. Available from: http://www.who.int/workforcealliance/countries/pak/ en/

20. Schneider Z. Developing a research proposal. In Schneider Z, Elliott D, LoBiondo-Wood D, Haber J, editors. Nursing research: methods, critical appraisal and utilisation. 2nd ed. Marrickville, NSW: Mosby Elsevier; 2003. p. 123-136. 
21. Silverman D. Interpreting Qualitative Data. 2nd

ed. Thousand Oaks, California: SAGE Publications;

2001.

22. Pope C, Ziebland S, Mays N. Qualitative research in health care: analysing qualitative data. BMJ. 2000;320(7227):114-116.

23. Miles MB, Huberman AM. Qualitative Data Analysis. Thousand Oaks, California. SAGE Publications; 1994.

24. Lincoln YS, Guba EG. Naturalistic Inquiry. Newbury Park, California. SAGE Publications; 1985.

25. Hagen-Zanker J. Why do people migrate? A review of the theoretical literature. Maastricht: Maastricht Graduate School of Governance, Maastricht University, The Netherlands; 2008. Working Paper No.: MGSo/2008/WP002.

26. Tolhurst H. Landscape of fulfilment: a model for understanding rural medical recruitment and retention [PhD thesis]. Newcastle (NSW): University of Newcastle, Australia; 2008.

27. Abdullah MA, Mukhtar F, Wazir S, Gilani I, Gorar Z, Shaikh BT. The health workforce crisis in Pakistan: a critical review and the way forward. World Health Popul. 2014;15(3):4-12.

28. Haq Z, labal Z, Rahman A. Job stress among community health workers: a multi-method study from Pakistan. Int J Ment Health Syst. 2008;2(15):1-6.

29. Mazhar A, Shaikh BT. Reforms in Pakistan: decisive times for improving maternal and child health. Helathc Policy. 2012;8(1):24-32. 